Research Paper

\title{
AKR1B10 Inhibitor Epalrestat Facilitates Sorafenib-Induced Apoptosis and Autophagy Via Targeting the mTOR Pathway in Hepatocellular Carcinoma
}

\author{
Nan Geng ${ }^{1}$, Yuanyuan Jin ${ }^{2}$, Yurong $\mathrm{Li}^{1}$, Shixuan Zhu1 ${ }^{1}$, and Han Bai ${ }^{1, 凶}$ \\ 1. Department of Infectious Disease, Shengjing Hospital of China Medical University, Shenyang 110004, China \\ 2. Laboratory of Biomaterials and Translational Medicine, The Third Affiliated Hospital, Sun Yat-Sen University, Guangzhou 510630, China \\ $\triangle$ Corresponding author: baih@sj-hospital.org, Tel.: +86-1894-025-6947
}

(C) The author(s). This is an open access article distributed under the terms of the Creative Commons Attribution License (https://creativecommons.org/licenses/by/4.0/). See http://ivyspring.com/terms for full terms and conditions.

Received: 2019.12.11; Accepted: 2020.05.04; Published: 2020.05.18

\begin{abstract}
Sorafenib is the standard systemic treatment for advanced hepatocellular carcinoma (HCC), and improving its therapeutic effects is crucial for addressing cancer aggression. We previously reported that epalrestat, an aldo-keto reductase 1B10 inhibitor, enhanced sorafenib's inhibitory effects on HCC xenograft in nude mice. This study aimed to elucidate the mechanism of epalrestat's anti-tumour enhancing effects on sorafenib. HepG2 cells were treated with sorafenib, epalrestat, and their combination. Cell proliferation was assessed with Cell Counting Kit-8 and colony formation assays. AKR1B10 supernate concentration and enzyme activity were detected by ELISA assay and the decrease of optical density of NADPH at $340 \mathrm{~nm}$. Cell cycle and apoptosis analyses were performed with flow cytometry. Western blots clarified the molecular mechanism underlying effects on cell cycle, apoptosis, and autophagy. The anti-tumour mechanism was then validated in vivo through TUNEL and immunohistochemistry staining of HCC xenograft sections. Epalrestat combined with sorafenib inhibited HepG2 cellular proliferation in vitro, arrested the cell cycle at G0/G1, and promoted apoptosis and autophagy. Treatment with a specific mTOR activator MHY-1485 increased mTOR phosphorylation, while suppressing apoptosis and autophagy. Consistent with in vitro results, data from the HCC-xenograft nude mouse model also indicated that combined treatment inhibited the mTOR pathway and promoted apoptosis and autophagy. In conclusion, epalrestat heightens sorafenib's anti-cancer effects via blocking the mTOR pathway, thus inducing cell cycle arrest, apoptosis, and autophagy.
\end{abstract}

Key words: hepatocellular carcinoma, AKR1B10, sorafenib, apoptosis, autophagy, mTOR signalling pathway

\section{Introduction}

Hepatocellular carcinoma (HCC) is a highly aggressive malignant tumour and the fourth leading cause of cancer-related death worldwide [1]. Due to synergistic effects of hepatitis B and C infection, obesity, and alcohol consumption, HCC incidence is steadily rising [2]. Survival rate of advanced HCC is extremely poor because of lower differentiation, insidious onset, rapid cancer recurrence, and low sensitivity to chemotherapy drugs [3]. Sorafenib, a tyrosine kinase inhibitor, is the standard systemic treatment for advanced HCC [4]. The drug primarily inhibits angiogenesis and tumour development through targeting vascular endothelial growth factor and the Raf/MAPK signalling pathway [5]. However, the clinical outcome in patients with advanced HCC is far from satisfactory, indicating a crucial need for improving sorafenib's therapeutic effect.

The aldo-keto reductase family 1 member B10 (AKR1B10) is a member of the aldo-keto-reductase superfamily, normally expressed in small and large intestines [6]. The protein converts carbonyl compounds on aldehydes or ketones to alcohols for 
detoxification and promotes de novo synthesis of fatty acids, regulating retinoic-acid metabolism and promoting cell proliferation. Highly expressed in liver cancer [7], AKR1B10 is closely related to clinical staging, HCC prognosis [8], and sensitivity to chemotherapeutic drugs [9]. Our previous clinical studies showed that elevated serum AKR1B10 was related to diagnosis of early-stage $\mathrm{HCC}[10,11]$. Additionally, experimental studies in nude mice revealed that when combined with the AKR1B10 inhibitor epalrestat, sorafenib's inhibitory effects on HCC xenograft were enhanced [12]. However, the mechanism of this enhancement remains unclear.

In this study, we performed in vitro and in vivo experiments to investigate the mechanism underlying epalrestat-induced enhancement of sorafenib's anti-tumour effects. Our work should provide a new therapeutic target for the treatment of patients with advanced HCC.

\section{Materials and Methods}

\section{Cell culture}

Human hepatocyte L02 cell line and HCC cell lines including HepG2, Huh-7 and PLC/PRF/ 5 were purchased from the Type Culture Collection of the Chinese Academy of Sciences (Shanghai, China). L02, HepG2 Cells were cultured in RPMI-1640 medium and Huh-7, PLC/PRF/ 5 cells were cultured in high glucose DMEM medium supplemented with $10 \%$ foetal bovine serum (FBS) and $1 \%$ penicillin-streptomycin (Biological Industries, Kibbutz Beit Haemek, Israel) in a 5\% CO2, humidified atmosphere at $37^{\circ} \mathrm{C}$.

\section{Chemicals and antibodies}

Sorafenib (CAS, 284461-73-0), epalrestat (CAS, 82159-09-9) (Selleck Chemicals, Houston, TX, USA) and MHY-1485(CAS, 326914-06-1) (MedChem Express, Monmouth Junction, NJ, USA) were dissolved in dimethyl sulfoxide (Sigma-Aldrich, St. Louis, MO, USA) to produce 40,20 and $10 \mathrm{mmol} / \mathrm{L}$ stock solutions, respectively. Solutions were stored at $-20^{\circ} \mathrm{C}$. Rabbit monoclonal antibodies against phosphorylated retinoblastoma protein $(\mathrm{p}-\mathrm{Rb}$ Ser807/811), cyclin D1, cyclin E1, caspase-3, cleaved caspase-3, B-cell lymphoma-2 (Bcl-2), extracellular regulated kinase (ERK), p-ERK (Tyr202/204), protein kinase B (AKT), p-AKT (Ser473), and mammalian target of rapamycin (mTOR) were purchased from Cell Signalling Technology (Danvers, MA, USA). Rabbit monoclonal antibodies against p-mTOR (S2448), BCL2-Associated X (Bax), Bcl-2-interacting protein-1 (Beclin-1), and microtubule-associated protein light chain-3 (LC3) were from Abcam (Cambridge, MA, USA). Rabbit monoclonal antibodies against AKR1B10 were from Invitrogen (Carlsbad, CA, USA). Rabbit monoclonal antibodies against GAPDH, $\beta$-actin, and $\beta$-tubulin were from Wanleibio (Shenyang, China).

\section{Cell viability assay}

A Cell Counting Kit-8 assay (CCK-8; Do Jindo Molecular Technologies Inc., Kumamoto, Japan) was used to determine cell proliferation post-drug treatment. HepG2 cells were seeded in a 96-well plate $\left(5 \times 10^{3}\right.$ cells/well $)$ and cultured in $100 \mu \mathrm{L}$ of RPMI-1640 supplemented with 10\% FBS for $24 \mathrm{~h}$. Next, cultures were replaced with different concentrations of epalrestat, sorafenib, and their combination. After incubation at $37^{\circ} \mathrm{C}$ for 24,48 , or 72 $\mathrm{h}$, the medium was replaced with $90 \mu \mathrm{L}$ of RPMI-1640 and $10 \mu \mathrm{L}$ of CCK-8 reagent. Cells were incubated for $2 \mathrm{~h}$ at $37^{\circ} \mathrm{C}$. Finally, optical density was measured using a microplate reader (elx808; BioTek Instruments Inc., Winooski, VT, USA) at $450 \mathrm{~nm}$.

\section{Colony formation assay}

The HepG2 cells were seeded into a six-well plate at $10^{3}$ cells/well in RPMI-1640 medium with $10 \%$ FBS and incubated for $24 \mathrm{~h}$. Subsequently, 75 $\mu \mathrm{mol} / \mathrm{L}$ epalrestat, $8 \mu \mathrm{mol} / \mathrm{L}$ sorafenib, and their combination was added to the cultures. After a 14-d incubation, cells were washed three times with PBS, fixed with $4 \%$ paraformaldehyde for $20 \mathrm{~min}$, and stained for $5 \mathrm{~min}$ using crystal violet (Beyotime Institute of Biotechnology, Shanghai, China). The remaining dye was removed with ddH2O. Finally, colonies including $>50$ cells were counted to determine colony formation rate [(number of clones/number of cells inculcated) $\times 100 \%]$.

\section{ELISA assay of Supernates concentration of AKRIB 10}

After treated with $8 \mu \mathrm{mol} / \mathrm{L}$ sorafenib, 75 $\mu \mathrm{mol} / \mathrm{L}$ epalrestat and the combination for $24 \mathrm{~h}$, cell culture supernates were collected to detect AKR1B10 concentration by enzyme-linked immunosorbent assay (ELISA) kits (USCN, Wuhan, China). According to the manufacturer's instructions, samples were centrifuged for 20 minutes at $1,000 \times \mathrm{g}$, followed by adding $100 \mu \mathrm{L}$ each of dilutions of standard and samples into the appropriate wells and incubating for 1 hour at $37^{\circ} \mathrm{C}$. Then added Detection Reagent A, Detection Reagent B, Substrate Solution, and Stop Solution respectively. Finally, optical density was measured using a microplate reader (BioTek Instruments Inc., Winooski, VT, USA) at $450 \mathrm{~nm}$.

\section{AKR IB 10 enzyme activity assay}

The reductase activities in the cell extracts were determined by the decrease in the absorbance of 
nicotinamide adenine dinucleotide phosphate $(\mathrm{NADPH})$ at $340 \mathrm{~nm} \quad\left(\varepsilon_{340}=6220 \mathrm{M}^{-1} \mathrm{~cm}^{-1}\right)$. Cells treated with $8 \mu \mathrm{mol} / \mathrm{L}$ sorafenib, $75 \mu \mathrm{mol} / \mathrm{L}$ epalrestat and the combination were lysed on ice in radioimmunoprecipitation buffer, supplemented with $1 \%$ PMSF, followed by centrifugation at $13000 \mathrm{rpm}$ at $4^{\circ} \mathrm{C}$ for 20 minutes. The reaction mixture consisted of phosphate buffer saline (PH 7.0), $20 \mathrm{mM}$ DL-glyceraldehyde, $0.3 \mathrm{mM}$ NADPH and $50 \mu \mathrm{g}$ Soluble proteins in a total volume of $150 \mu \mathrm{L}$. The decrease in optical density at $340 \mathrm{~nm}$ is monitored for $20 \mathrm{~min}$ at $37^{\circ} \mathrm{C}$ in a microplate reader (BioTek Instruments Inc., Winooski, VT, USA) at $340 \mathrm{~nm}$. One unit $(\mathrm{U})$ of enzyme activity was defined as the amount of enzyme that catalyzes the oxidation of $1 \mu \mathrm{M}$ NADPH per minute at $37^{\circ} \mathrm{C}$ [13].

\section{Apoptosis and cell-cycle analysis}

Cell apoptosis was determined using an Annexin $\mathrm{V} /$ propidium iodide (PI) apoptosis detection kit (BD Biosciences, Sunnyvale, CA, United States). The total apoptotic rate was characterized as the percentage of cells with Annexin V positive for early apoptosis and both Annexin V/propidium iodide (PI) positive for late apoptosis. HepG2 cells were seeded in six-well plates at $2 \times 10^{5}$ cells/well. After $24 \mathrm{~h}$ of incubation, drugs $(75 \mu \mathrm{mol} / \mathrm{L}$ epalrestat, $8 \mu \mathrm{mol} / \mathrm{L}$ sorafenib, or combination) were added to the culture medium for another $24 \mathrm{~h}$ of incubation, followed by staining for 15 min with Annexin V-FITC and PI in darkness. For cell-cycle analysis, treated cells were fixed with $70 \%$ ethanol for $12 \mathrm{~h}$ at $4^{\circ} \mathrm{C}$ before being washed three times with pre-cooled PBS. Cells were stained with RNase A for $30 \mathrm{~min}$ at $37^{\circ} \mathrm{C}$ and with PI (Solarbio, Beijing, China) for $15 \mathrm{~min}$ at $4^{\circ} \mathrm{C}$, both in darkness. Apoptosis and DNA content were quantified using the BD FACScalibur flow cytometer.

\section{Immunofluorescence detection of $\mathbf{p}-\mathbf{R b}$ and LC3}

HepG2 cells were cultured on glass coverslips to a suitable density before the addition of $75 \mu \mathrm{mol} / \mathrm{L}$ epalrestat, $8 \mu \mathrm{mol} / \mathrm{L}$ sorafenib, or their combination for $12 \mathrm{~h}$. Cells were fixed for $20 \mathrm{~min}$ with $4 \%$ paraformaldehyde and permeabilised with Triton X-100 (0.2\%) in PBS for 15 min. Unspecific binding sites were blocked with goat serum for $30 \mathrm{~min}$. Coverslips were incubated with primary antibody against LC3 (1:200 diluted, Abcam) or p-Rb (1:400 diluted, CST) overnight, followed by incubation with fluorescein isothiocyanate (FITC)-labelled anti-rabbit IgG antibody (Abcam) for $1 \mathrm{~h}$ at room temperature. Cell nuclei were stained with 4',6-diamidino-2-phenylindole (DAPI) for $5 \mathrm{~min}$. A confocal laser scanning microscope (Nikon, Japan) was used for image capture.

\section{Western blots}

Cells were treated with $8 \mu \mathrm{mol} / \mathrm{L}$ sorafenib, 75 $\mu \mathrm{mol} / \mathrm{L}$ epalrestat, or combination of $75 \mu \mathrm{mol} / \mathrm{L}$ epalrestat and $8 \mu \mathrm{mol} / \mathrm{L}$ sorafenib for $24 \mathrm{~h}$. For rescue experiment, cells were treated with $10 \mu \mathrm{M}$ mTOR activator MHY-1485 for $6 \mathrm{~h}$ prior to treatment with the combination of sorafenib and epalrestat. Treated cells were lysed in radioimmunoprecipitation assay lysis buffer (Beyotime Institute of Biotechnology, Haimen, China), supplemented with $1 \%$ phenylmethanesulfonylfluoride (PMSF) and 1\% phosphatase inhibitor cocktail. The mixture was centrifuged at $13,800 \times g$ at $4^{\circ} \mathrm{C}$ for $20 \mathrm{~min}$. Each well contained $25 \mu \mathrm{g}$ of protein in a total volume of $10 \mu$ l. Proteins were visualised using chemiluminescence reagents (GE Healthcare Life Sciences, Pittsburgh, PA, USA) and detected with a chemiluminescence detection system (GE Amersham Imager 600). Protein bands were quantitated in ImageJ software.

\section{Immunohistochemistry (IHC) staining}

Tumour tissues were obtained from previous animal experiments [12], all approved by the Animal Experimental Ethics Committee of the Shengjing Hospital of China Medical University (project identification code: 2017PS332K). Briefly, $1 \times 10^{7}$ HepG2 cells were resuspended in 100ul culture medium and 100ul BD Matrigel, and the cell suspension were injected into the right side neck of nude mice. One week later, the mice were randomly divided into four groups: control, sorafenib (30 $\mathrm{mg} / \mathrm{kg})$, epalrestat $(100 \mathrm{mg} / \mathrm{kg})$, and combination (30 $\mathrm{mg} / \mathrm{kg}$ sorafenib and $100 \mathrm{mg} / \mathrm{kg}$ epalrestat) group. The drugs were admitted by gavage, 6 times/week for two weeks. The mice were then sacrificed, and tumours were fixed. Paraffin sections were deparaffinised in xylene and rehydrated in ethanol and water. Sections were stained according to the SPlink Detection kit protocol (Zhongshan Golden Bridge Biotechnology Co. Ltd., Beijing, China), then incubated overnight at $4^{\circ} \mathrm{C}$ with primary antibodies against LC3 (1:200 dilution) or p-mTOR (1:100 dilution) for $30 \mathrm{~min}$, followed by incubation with biotinylated anti-rabbit antibody and streptavidin/ horseradish peroxidase at $37^{\circ} \mathrm{C}$. Peroxidase reaction proceeded with 3,3-diaminobenzidine as the substrate; nuclei were stained with haematoxylin for 1 min. Images were then captured with a light microscope (Nikon, Japan); five images/samples were analysed using NIS-Elements Br3.0 software.

\section{TUNEL assay}

In situ detection of apoptotic cells was performed with a TUNEL assay kit, following the 
manufacturer's protocol (Zhongshan Golden Bridge Biotechnology Co. Ltd.). Sections were deparaffinised in xylene and rehydrated in ethanol and water. Cell nuclei were stained with DAPI for $5 \mathrm{~min}$. Images were then captured with a light microscope (Nikon, Japan); five images/samples were analysed using NIS-Elements Br3.0 software.

\section{Statistical analysis}

All experiments were repeated independently three times and data were shown as means \pm standard deviation. Statistical analyses were performed using SPSS 24.0 and significant differences were analysed by One-way analyses of variance (ANOVA) coupled with post hoc comparisons. Significance was defined as $P<0.05$.

\section{Results}

\section{Epalrestat enhances the effect of sorafenib on proliferation inhibition and cell-cycle arrest in HCC}

Western blot assay was used to detect AKR1B10 expression level in L02 and HepG2, Huh-7 and PLC/PRF/ 5 cell lines. We chose HepG2 cells with the highest AKR1B10 expression among the HCC cell lines for following studies (Figure 1A and B).
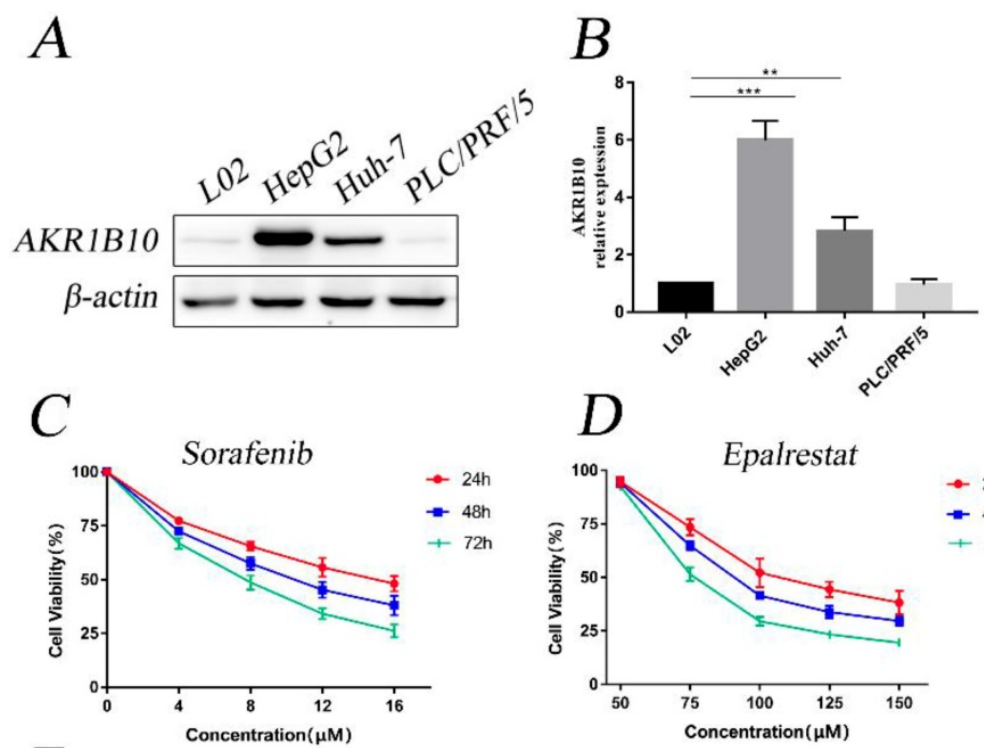

F
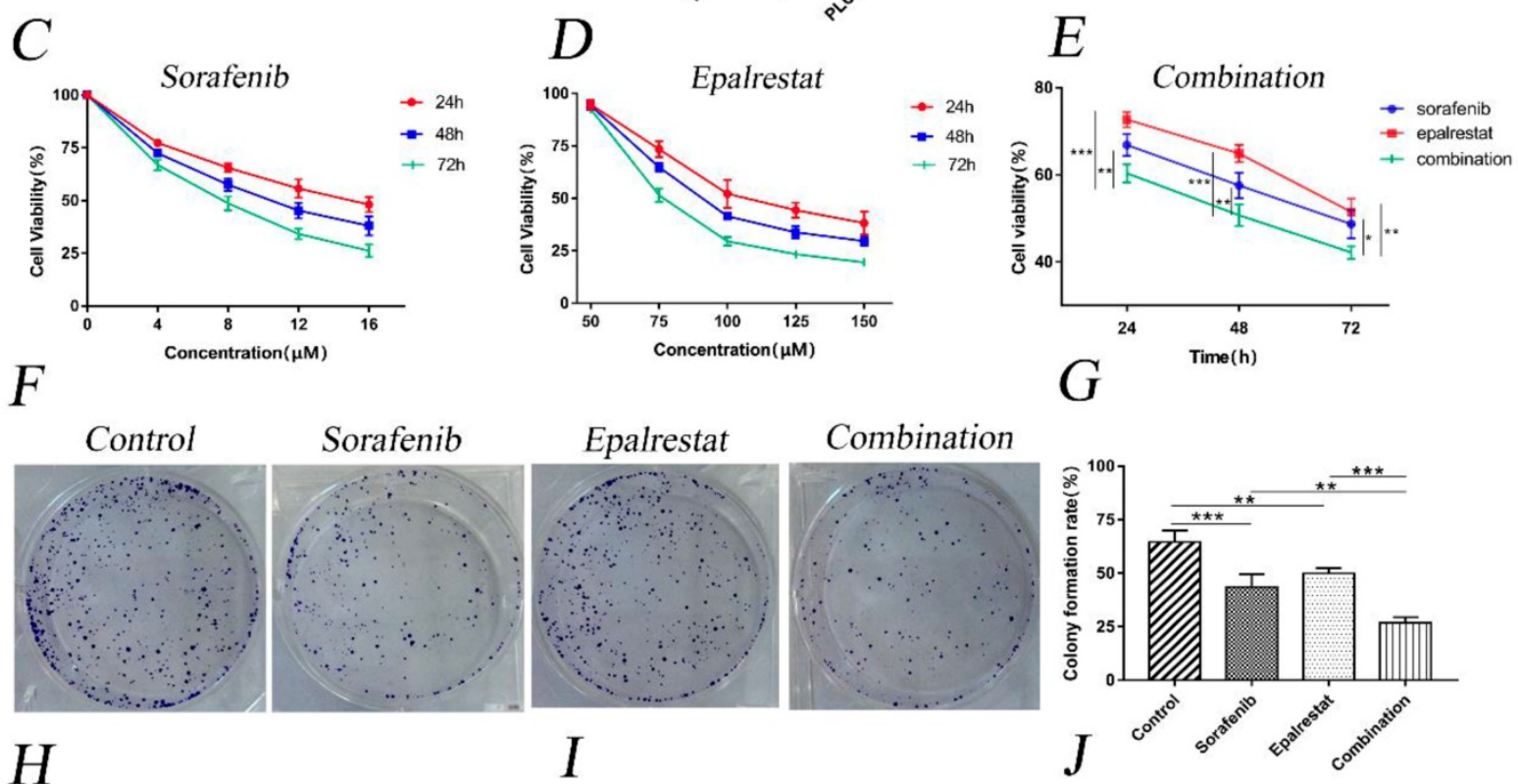

Combination

$H$

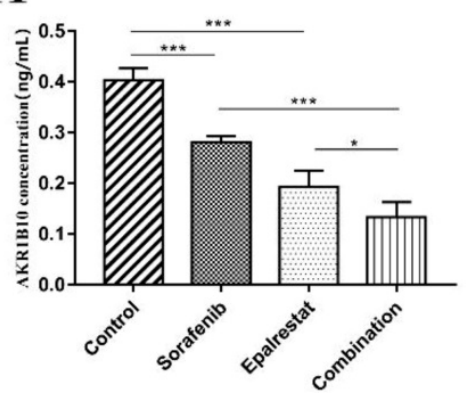

Sorafenib Epalrestat

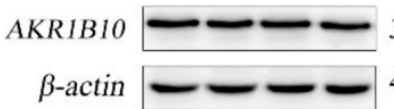

4
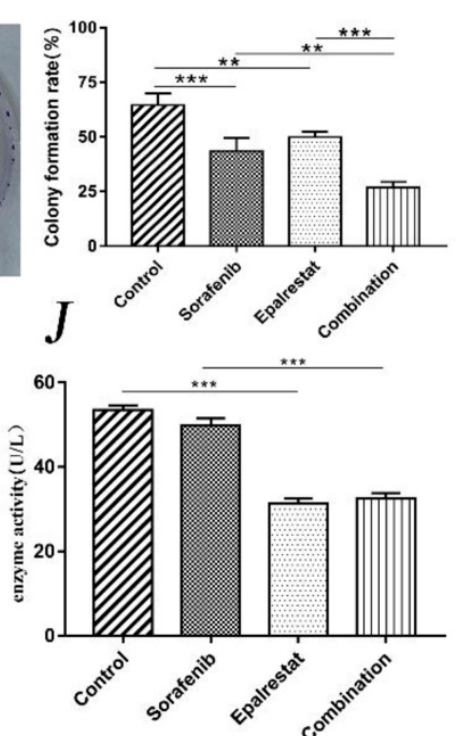

Figure 1. Combination treatment of sorafenib and epalrestat inhibited HepG2 proliferation. (A, B) Western blot was used to test the expression of AKR1B10 in hepatocyte L02 and HCC cell lines including HepG2, Huh-7 and PLC/PRF/5. (C-E) CCK-8 assay was used to detect HepG2 cellular viability after treatment with various concentrations of sorafenib $(4,8,12$ and $16 \mu \mathrm{M})$, epalrestat $(50,75,100,125$ and $150 \mu \mathrm{M})$ and combination of $8 \mu \mathrm{M}$ sorafenib and $75 \mu \mathrm{M}$ epalrestat for 24,48 and $72 \mathrm{~h}$ in $\mathrm{HepG} 2$ cells. $(F, G)$ Colony formation assay of HepG2 cells in the single-agent or combination treatment. After $24 \mathrm{~h}$ treatment with $8 \mu \mathrm{M}$ sorafenib, $75 \mu \mathrm{M}$ epalrestat 
CCK-8 assay revealed that sorafenib inhibited HepG2 cell proliferation with half-inhibitory concentration (IC50) ranging between 8 and $16 \mu \mathrm{M}$ (Figure 1C). However, epalrestat had no significant effect at low concentrations (Figure 1D). Notably, combining $8 \mu \mathrm{M}$ sorafenib and $75 \mu \mathrm{M}$ epalrestat significantly suppressed growth of HepG2 cells more than either monotherapy (Figure 1E). The colony formation assay revealed a comparable effect. After treatment with sorafenib or epalrestat for $14 \mathrm{~d}$, HepG2 colony formation decreased significantly compared with control rates. Combined therapy reduced colony formation rate more than monotherapy (Figure $1 \mathrm{~F}$ and G).

Since AKR1B10 is a secretory protein [14]. Enzyme-linked immunosorbent assay (ELISA) was used to evaluate AKR1B10 levels in cell culture supernates. The assay showed epalrestat and sorafenib could inhibit AKR1B10 secret, while the combined therapy performed a higher effect than monotherapy (Figure 1H). Western blot assay revealed that the expression of AKR1B10 showed no change in HepG2 cells treated with sorafenib, epalrestat and the combination (Figure 1I). To determine the effect of epalrestat monotherapy and the combination on AKR1B10 activity, reduced $\mathrm{NADPH}$ at $340 \mathrm{~nm}$ was used to measure AKR1B10 enzyme activity. The assay showed epalrestat could inhibit AKR1B10 enzyme activity, while no differences were identified in sorafenib compared with the untreated cells. Further, the combined therapy showed no differences between the epalrestat monotherapy (Figure 1J).

Cell-cycle progression determines tumour proliferation [15]. Here, sorafenib monotherapy increased the percentage of G1 cells compared with that in the control $(53.18 \pm 2.22$ vs $47.23 \pm 1.10, P=0.001)$. Epalrestat treatment and control did not differ $(49.21 \pm 1.61$ vs $47.23 \pm 1.10, P=0.146)$. However, combination therapy significantly increased the proportion of cells arrested at G0/G1 than sorafenib monotherapy $(58.78 \pm 0.68$ vs $53.18 \pm 2.22, \quad P=0.002)$ (Figure 2A and B).

Cyclin, cyclin-dependent kinase (CDK), and transcription factor E2F1 regulate the cell cycle. Additionally, $\mathrm{p}-\mathrm{Rb}$ specifically regulates the $\mathrm{G} 1$ to $\mathrm{S}$ transition. Our western blot results showed that while sorafenib and epalrestat monotherapy reduced the expression of cyclin D1, cyclin E1, and $\mathrm{p}-\mathrm{Rb}$, combination therapy had a stronger inhibitory effect on all three proteins (Figure $2 \mathrm{C}$ and $\mathrm{D}$ ). Immunofluorescence assay identified a significant reduction in nuclear $\mathrm{p}-\mathrm{Rb}$ expression under combination treatment (Figure 2E and F). These results demonstrated that sorafenib and epalrestat together enhanced anti-proliferative effects through inducing G0/G1 cell-cycle arrest in HCC.

\section{Epalrestat promotes sorafenib-induced cell apoptosis in HCC}

Apoptosis is impaired during progression toward malignancy, leading to excessive cell proliferation. Promoting cancer cell apoptosis is therefore a goal for anti-cancer therapy. After treated with sorafenib, epalrestat monotherapy or combination for 24h, Annexin V/PI staining revealed the total apoptotic rate of control, sorafenib, epalrestat monotherapy and combination were $8.33 \pm 0.65$, $13.40 \pm 1.41,10.99 \pm 0.59,19.69 \pm 1.26$ respectively. Both sorafenib and epalrestat monotherapy increased total HepG2 apoptotic rate compared with that in the control. Under combination treatment, total apoptotic rate was significantly higher than that of monotherapy.

Caspase- 3 and its activated, cleaved form are apoptosis effectors. Additionally, pro-apoptotic protein Bax and anti-apoptotic protein Bcl-2 play key roles in maintaining apoptosis balance [16]. Western blots revealed that both sorafenib and epalrestat up-regulated Bax and cleaved caspase- 3 expression, while down-regulating Bcl-2 expression. Combination treatment increased both of these effects, thus enhancing apoptosis in HepG2 cells (Figure 3C and D).

\section{Epalrestat promotes sorafenib-induced cell autophagy in HCC}

Multiple stimuli activate the processes of autophagy and apoptosis to regulate cell death [17]. LC3-II is a specific marker for autophagy initiation [18]; additionally, Beclin-1 complexation with Atg14 and VPS34 contributes to autophagosome nucleation [19]. Here, western blot results showed that sorafenib and epalrestat monotherapy up-regulated Beclin-1 expression and promoted LC3 type I-to-type-II conversion, suggesting the activation of autophagy. Combination therapy significantly up-regulated Beclin-1 and LC3-II expression more dramatically than monotherapy (Figure 4A and B). Consistent with western blots, immunofluorescence also showed that LC3 was distributed in the cytoplasm, with significantly up-regulated expression under combined therapy (Figure 4C). These results reported that sorafenib and epalrestat combination activated autophagy in tumour cells.

\section{Sorafenib and epalrestat combination activates apoptosis and autophagy via inhibiting the mTOR pathway}

The serine/threonine kinase mTOR plays an important role in regulating autophagy, proliferation, 
and angiogenesis [20]. The mTOR pathway is co-regulated through MAPK and AKT signalling pathways [21]. Our western blots showed that sorafenib and epalrestat down-regulated p-ERK and p-AKT individually, while they both inhibited mTOR phosphorylation, with more significant inhibitory effect under combination treatment (Figure 5A and B).

To verify that the combination therapy induced apoptosis and autophagy via the mTOR signalling pathway, we treated HepG2 cells with the mTOR activator MHY-1485 prior to combined drug treatment. The results revealed that the combination increased the expression of Beclin-1, LC3 II, Bax, and cleaved caspase-3 while decreased the phosphorylation of p-mTOR compared with that of the control group. However, the combination-induced effect was significantly reversed by MHY-1485.These results further confirmed that sorafenib and epalrestat likely activate autophagy and apoptosis through targeting the mTOR pathway.

\section{Epalrestat and sorafenib combination reduces tumour growth in HCC xenograft model though targeting mTOR phosphorylation,}

Consistent with the in vitro results, TUNEL assays and LC3 staining in xenograft tumours also indicated that epalrestat facilitated sorafenib-induced apoptosis and autophagy (Figure 6A and B) (Figure $6 \mathrm{~A}$ and $\mathrm{C}$ ). Similarly, IHC staining revealed that sorafenib significantly inhibited p-mTOR phosphorylation, an effect enhanced under combination treatment (Figure 6A and D). These results further demonstrated that combination of epalrestat and sorafenib may promote apoptosis and activated autophagy by targeting the mTOR signalling pathway.
A

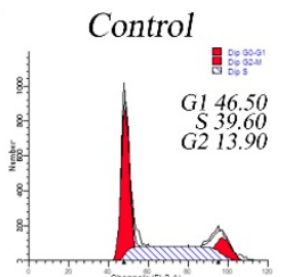

Epalrestat

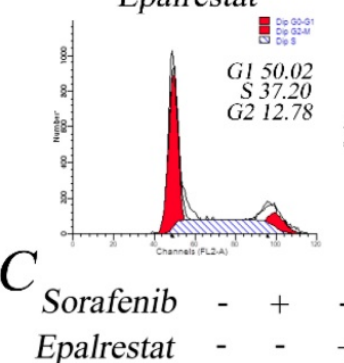

Epalrestat - - + +

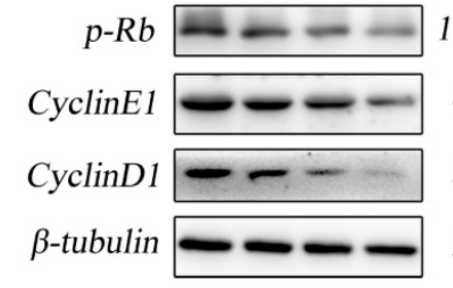

F

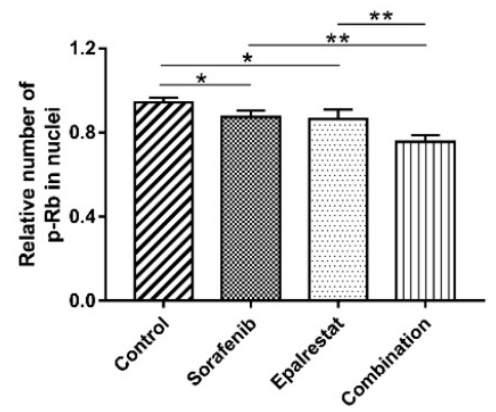

B

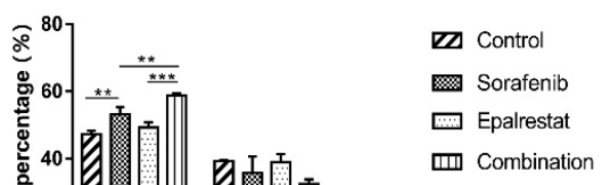

S 33.18
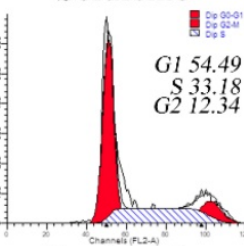

Combination

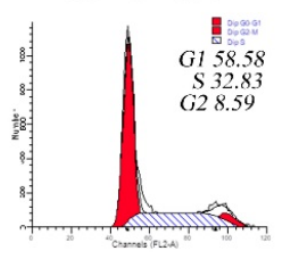

G1 $\stackrel{58.58}{5}$

S 32.83

8.59

$D$

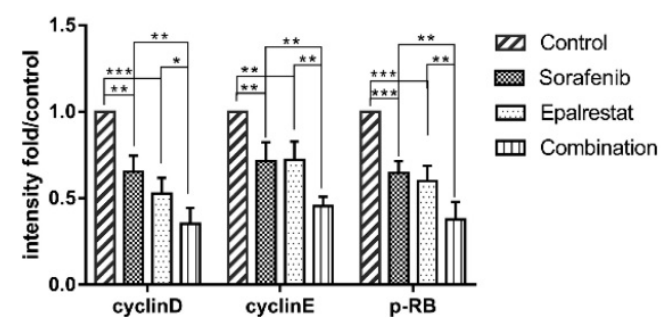

E
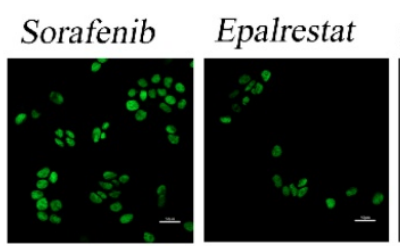

Combination

DAPI
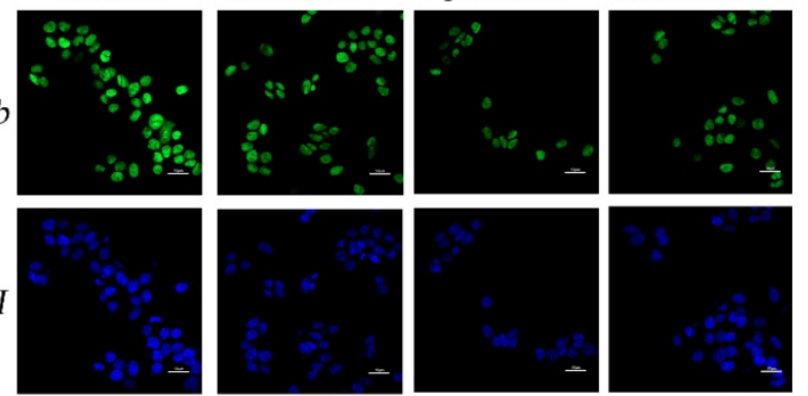

Merge
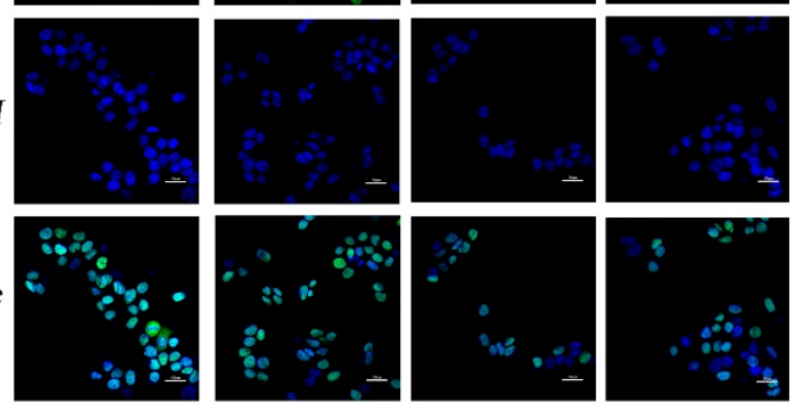

Figure 2. Combination treatment of sorafenib and epalrestat induced G0/G1 cell-cycle arrest of HepG2 cells. (A, B) cell cycle analysis using flow cytometry on HepG2 cells treated with $8 \mu \mathrm{M}$ sorafenib, $75 \mu \mathrm{M}$ epalrestat, and their combination for $24 \mathrm{~h}$. (C, D) Western blots of p-Rb, cyclin D1, and cyclin E1 after $24 \mathrm{~h}$ treatment with $8 \mu \mathrm{M}$ sorafenib, $75 \mu \mathrm{M}$ epalrestat, and combination. (E, F) Immunofluorescence assay detected nuclear $\mathrm{P}-\mathrm{Rb}$ expression $(400 \times)$. Data are mean $\pm \mathrm{SD}$. *, $\mathrm{P}<0.05$; $* *, \mathrm{P}<0.01 ; * * *, \mathrm{P}<$ 0.001 . 
A

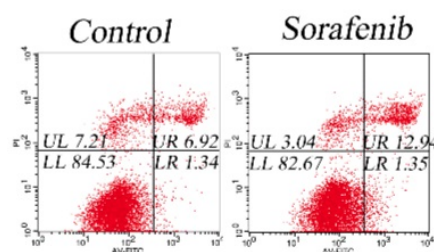

Epalrestat

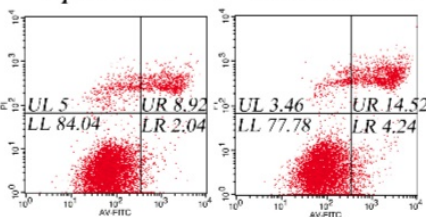

C

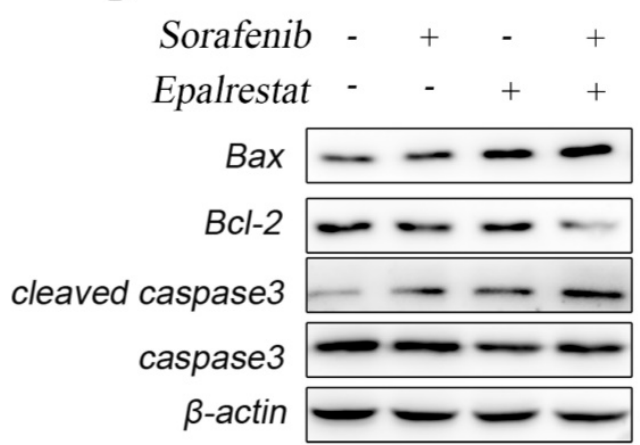

B

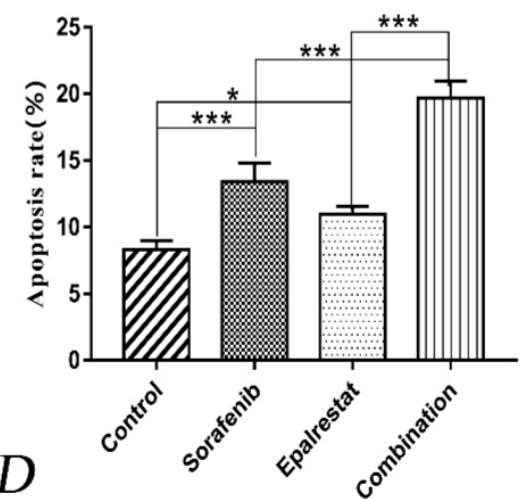

$21 \mathrm{kDa}$

$26 k D a$

$17 \mathrm{kDa}$

$35 \mathrm{kDa}$

$42 \mathrm{kDa}$

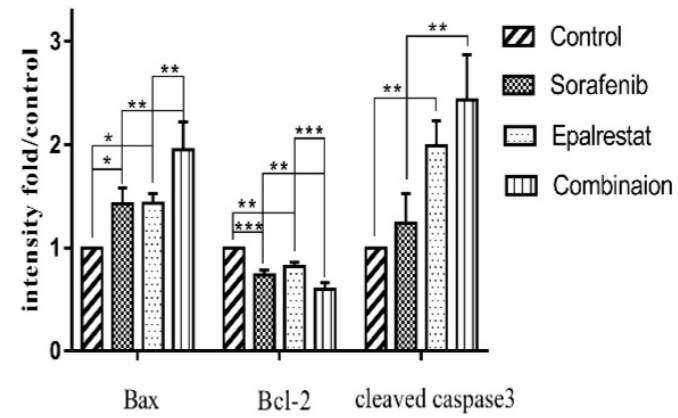

Figure 3. Sorafenib and epalrestat combination promoted apoptosis of HepG2 cells. (A, B) Apoptosis rate was evaluated with annexin V/PI staining. (C, D) Western blots of Bax, Bcl-2, caspase-3, and cleaved caspase-3, after treatment with $8 \mu \mathrm{M}$ sorafenib, $75 \mu \mathrm{M}$ epalrestat, and their combination for $24 \mathrm{~h}$. Data are mean \pm SD. *, $\mathrm{P}<0.05$; **, $\mathrm{P}<0.01$; ***, $\mathrm{P}<0.001$.

A

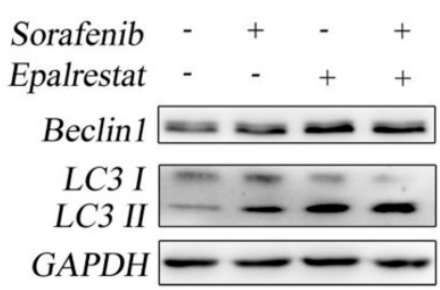

\section{B}

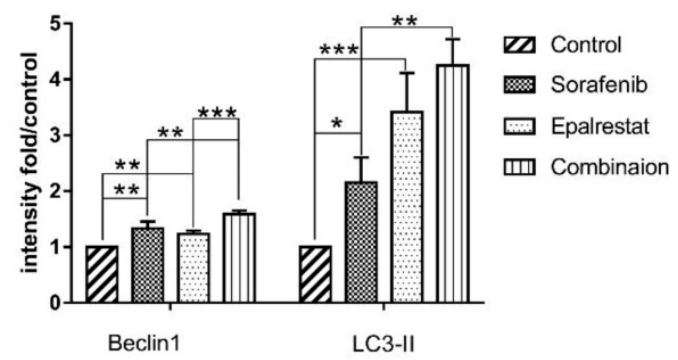

C

$52 \mathrm{kDa}$

$16 \mathrm{kDa}$

$14 \mathrm{kDa}$

$37 \mathrm{kDa}$
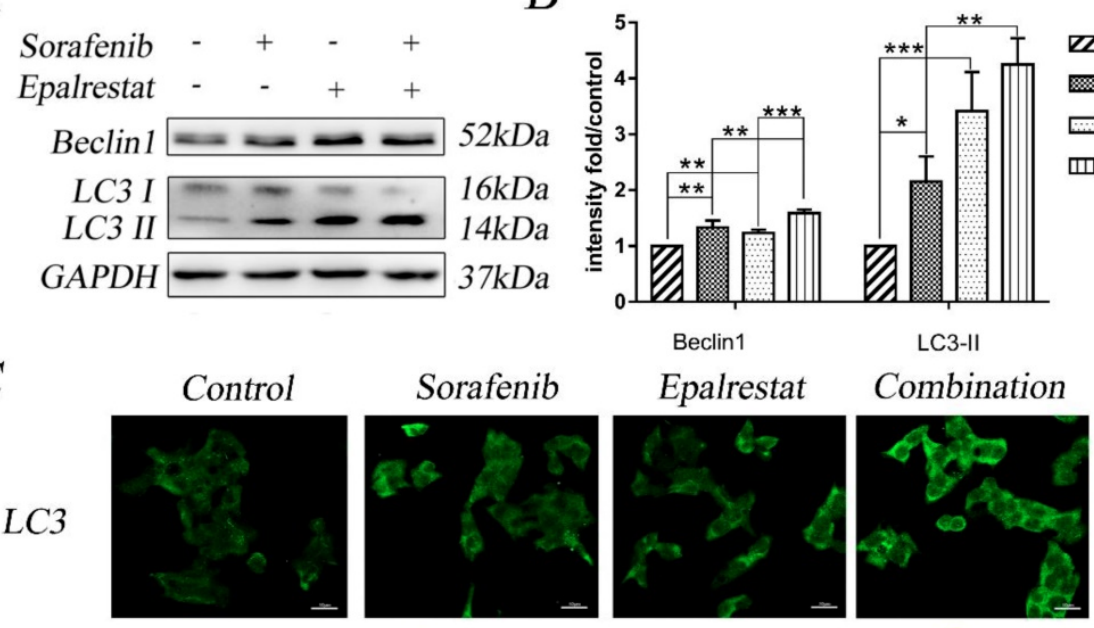

DAPI
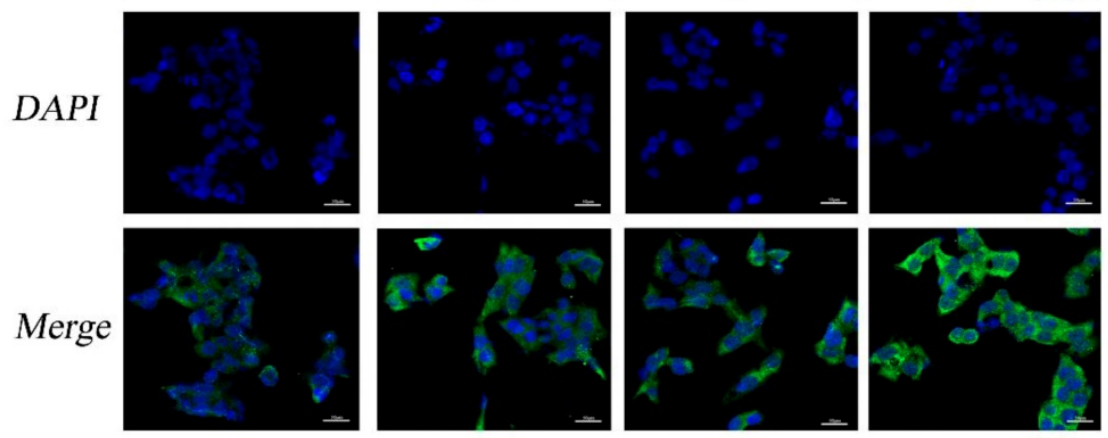

Figure 4. Combination treatment of sorafenib and epalrestat activated autophagy of HepG2 cells. (A, B) Treatment with $8 \mu M$ sorafenib, $75 \mu$ M epalrestat and the combination for $24 \mathrm{~h}$. Western blot was applied to detect the levels of Beclin 1 and LC3. (C) Immunofluorescence assay detected LC3 expression in cytoplasm (400x). Data are mean \pm SD. *, $\mathrm{P}<0.05 ; * *, \mathrm{P}<0.01 ; * * *, \mathrm{P}<0.001$. 


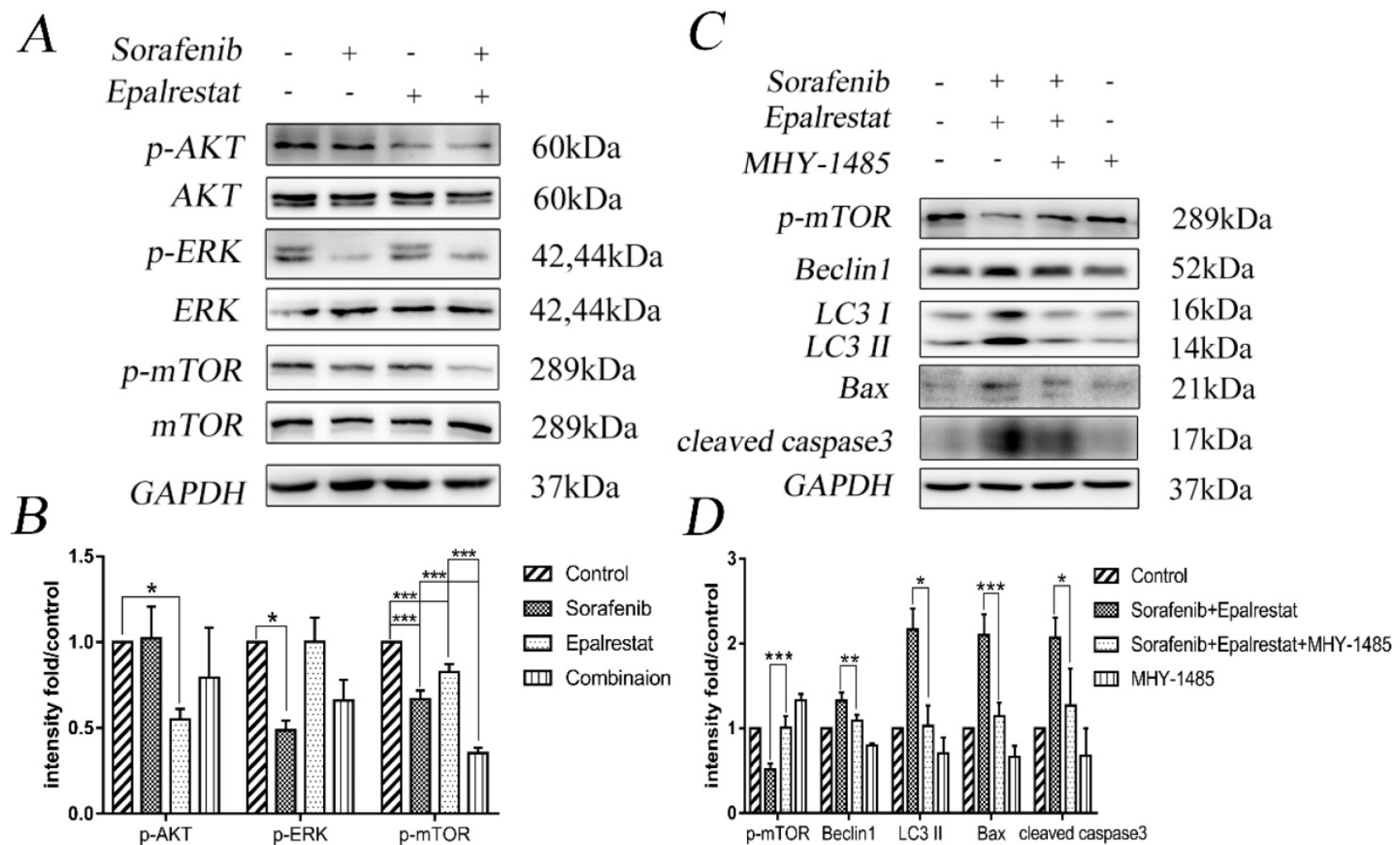

Figure 5. Sorafenib and epalrestat combination activated autophagy and apoptosis through inhibiting the $\mathbf{m T O R}$ pathway. (A, B) After $24 \mathrm{~h}$ treatment with 8 $\mu \mathrm{M}$ sorafenib, $75 \mu \mathrm{M}$ epalrestat, and their combination, western blots were applied to detect p-AKT, AKT, p-ERK (44/42), ERK (44/42), p-mTOR and mTOR. (C, D) HepG2 cells were treated with MHY-1485 for $6 \mathrm{~h}$ prior to the combination treatment, western blots were applied to detect P-mTOR Beclin 1, LC3 II, Bax, cleaved caspase3. Data are mean \pm SD. *, $\mathrm{P}<0.05 ;$ **, $\mathrm{P}<0.01 ; * * *, \mathrm{P}<0.001$.

A

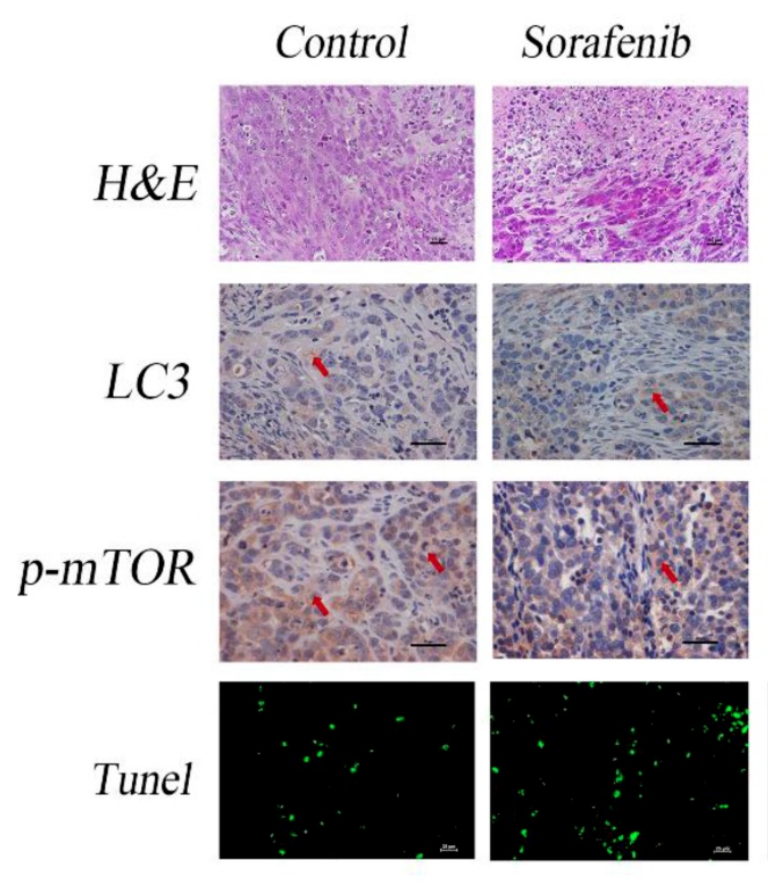

\section{$B$}
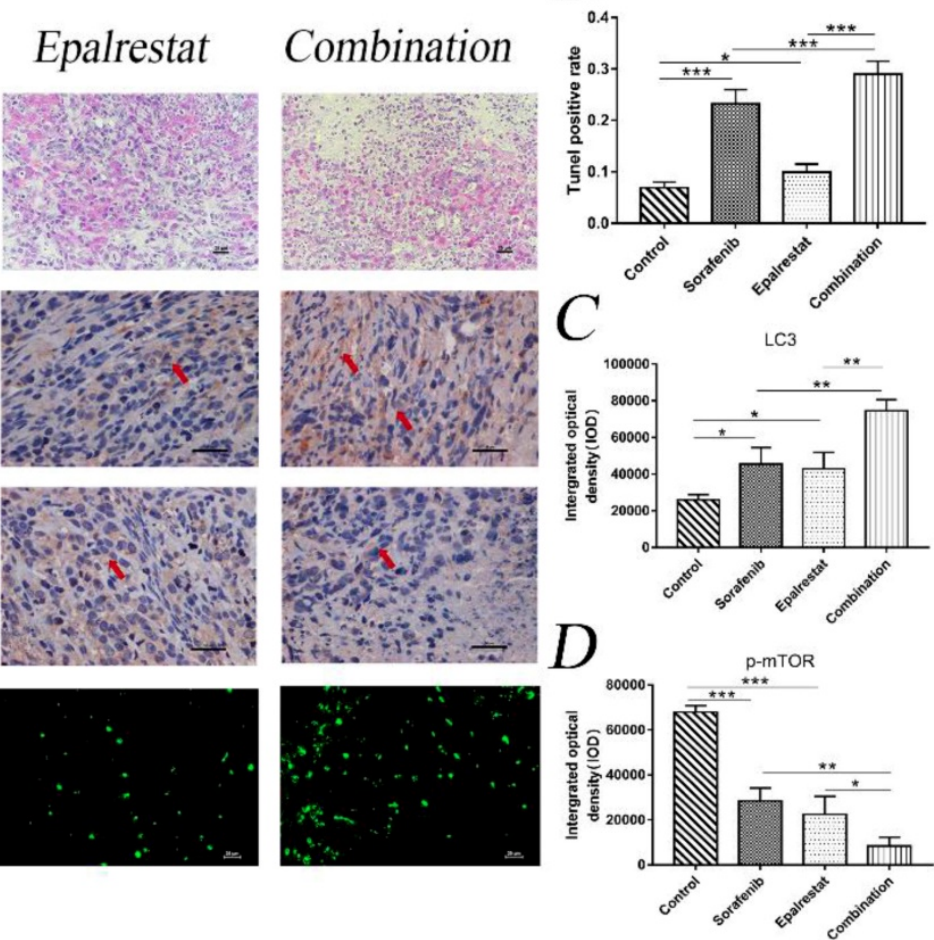

Figure 6. Sorafenib and epalrestat combination promoted apoptosis, autophagy, and reduced mTOR phosphorylation in HCC xenograft tissue. TUNEL assay and IHC staining of LC3 and p-mTOR were used to evaluate the levels of apoptosis, autophagy and p-mTOR in the combination treatment compared to monotherapy $(400 \times)$. Data are mean \pm SD. *, $\mathrm{P}<0.05 ; * *, \mathrm{P}<0.01 ; * * *, \mathrm{P}<0.001$. 


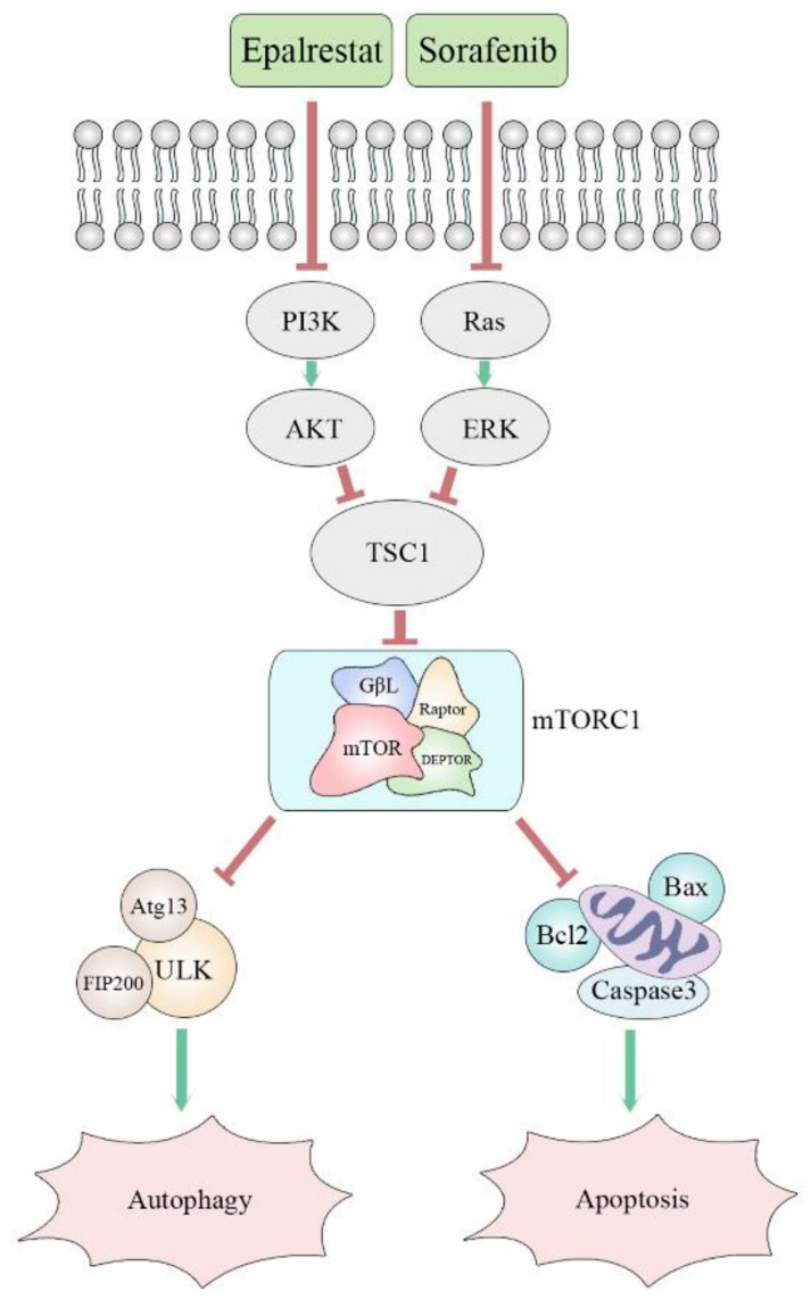

Figure 7. Proposed mechanism of synergistic effect of sorafenib and epalrestat on HCC.

\section{Discussion}

Sorafenib inhibits tumour angiogenesis and proliferation through targeting vascular endothelial growth factor receptor 2,3, platelet-derived growth factor receptor, and the MAPK signalling pathway [22]. Sorafenib also inhibits the expression of cyclin D1, Mcl-1, and survivin, all of which are involved in cell-cycle arrest and apoptosis [23]. Despite improvement in the survival benefit of advanced HCC by sorafenib, the median survival time of advanced HCC patients has only been extended by 3 months [4]. Furthermore, some patients experience tumour progression during sorafenib therapy and show a low response rate. Most advanced HCCs acquire resistance to sorafenib due to hypoxic microenvironment, abnormal activation of PI3K/AKT, tumour-initiating cells, and epithelialmesenchymal transition [24]. Thus, exploring combined strategies is a potentially effective way to improve sorafenib therapeutic effects.

AKR1B10 is a secretory protein and regarded as potential serum marker of hepatocellular carcinoma. It has been reported that AKR1B10 is secreted through a lysosome-mediated nonclassical pathway, leading to an increase in the serum of cancer patients[14]. Epalrestat is the AKR1B10 inhibitor, which inhibits its secretion and enzyme activity rather than its expression. In this study, we found epalrestat can inhibit AKR1B10 enzyme activity and concentration in cell culture supernates. Sorafenib had little effect on AKR1B10 enzyme activity, but it could reduce AKR1B10 concentration in the supernates. It is suggested that the inhibition of AKR1B10 secretion and enzyme activity may be the mechanism of epalrestat enhancing the efficacy of sorafenib.

Deregulated cell cycle and increased telomerase activity cause sustained cell proliferation and genomic instability, both of which are characteristic features of carcinogenesis [15]. Our results showed that combining sorafenib and epalrestat was more effective than monotherapy in significantly inhibiting cell proliferation and colony formation ability, as well as promoting G0/G1 cell-cycle arrest. We also demonstrated that monotherapy reduced cyclin D1, cyclin E1, and $\mathrm{p}-\mathrm{Rb}$ expression, with combination therapy exerting a stronger inhibitory effect. All of these proteins may play an important role in cell proliferation and cell-cycle arrest. The $\mathrm{Rb}$ protein inactivates transcription factor E2F1, which plays an important role in cell proliferation, through masking its transactivation domain. After the cyclin-CDK complex is formed, $\mathrm{Rb}$ is phosphorylated and releases E2F1, thereby driving the cell cycle from G1 to S [25]. Therefore, combination therapy enhanced antitumour effects through the mechanism of cell-cycle arrest.

Apoptosis maintains intracellular homeostasis, with the cascade activation of the caspase family playing a key role in initiation [16], while the Bcl-2 superfamily is important for regulation. Insertion of pro-apoptotic proteins Bax and Bak into the mitochondrial membrane releases cytochrome $\mathrm{c}$ into the cytoplasm. As a result, apoptotic bodies are synthesised to recruit and activate caspase- 9 and -3 , thus initiating apoptosis. Anti-apoptotic proteins Bcl2 and $\mathrm{Bcl}-\mathrm{xL}$ anchor to the mitochondrial membrane through their c-terminals, preventing apoptosis through inhibiting mitochondrial membrane permeability and cytochrome c release [26]. Because apoptosis plays an important role in tutor occurrence, development, and prognosis, anti-tumour therapy often targets apoptosis promotion [27]. Our results revealed that compared with monotherapy, combination treatment significantly increased total HepG2 apoptotic rate, along with Bax and cleaved caspase 3 expression, while decreasing Bcl-2 expres- 
sion. We confirmed that epalrestat promoted HCC apoptosis through regulating the $\mathrm{Bcl}-2 /$ caspase- 3 pathway, thus enhancing sorafenib anti-tumour effects.

Autophagy or type-II programmed cell death exerts a dual directional regulation effects on tumours. Occurring under stressors such as hypoxia or starvation, autophagic cells consume long-lived proteins or damaged organelles to maintain energy balance [28]. When induced by chemotherapeutic drugs, autophagy is considered an anti-tumour mechanism [29]. Sorafenib can induce autophagy in HCC [30], and sorafenib-resistant cells exhibit autophagy inactivation. Therefore, restoring autophagy is a therapeutic target for drug-resistant cancer cells [31]. Previous studies have shown that inhibiting aldose reductase causes accumulation of lipid peroxides such as 4-hydroxynonenal and acetaldehyde protein adducts; this accumulation then results in autophagy activation [32]. Here, we found that both sorafenib and epalrestat activated autophagy through increasing Beclin-1 and LC3 expression. Thus, enhanced autophagy appears to be a mechanism behind the improved therapeutic effects of combination therapy. Growing evidence has demonstrated that autophagy can regulate apoptosis through the mitochondrial pathway. Autophagyrelated proteins also play an important role in apoptosis. Beclin-1 contains the Bcl-2 homology-3 domain, which can bind to bcl-2, acting as a link between autophagy and apoptosis.

Many cancer cells, including HCC, exhibit up-regulation of mTOR. The protein mTORC1 regulates cell proliferation, apoptosis, angiogenesis, and autophagy through targeting its downstream molecules, including S6K, 4EBP1, HIF-1alpha, and ULK1 [33]. Both ERK and AKT signalling pathways are involved in mTOR pathway regulation. Specifically, AKR1B10 targets ERK signalling to regulate lipid metabolism, a role that appears to be carcinogenic in many tumours. Previous studies reported that AKR1B10 increased the synthesis of the lipid second messengers PIP2 and DAG in breast cancer cells, activating the Raf/MEK/ERK signalling pathway and promoting cancer cell proliferation [34]. However, in this study, epalrestat had no significant inhibitory effect on p-ERK, while sorafenib, as a MAPK inhibitor, had a significant inhibitory effect. The abnormal activation of the PI3K/AKT signalling pathway is linked to secondary sorafenib resistance. It is reported that aldose reductase inhibitor can promote G0/G1 cell cycle arrest of colon cancer cells by inhibiting PI3K/AKT/E2F1, and inhibit the proliferation and invasion by inhibiting PI3K/AKT/GSK3 $\beta[35,36]$. Our results indicated that epalrestat inhibited $\mathrm{p}$-AKT, while sorafenib had no significant effect. Both sorafenib and epalrestat decreased p-mTOR phosphorylation, an effect made stronger under combination therapy. Importantly, p-mTOR was found to be downregulated during combination treatment with sorafenib and epalrestat. However, MHY-1485, a mTOR activator, rescued the decreased level of p-mTOR. Moreover, increased phosphorylation of $\mathrm{p}$-mTOR reduced the apoptosis and autophagy induced by the combination treatment. Clearly, the mTOR signalling pathway is involved in the mechanism of the effect of combination treatment (Figure 7).

In conclusion, epalrestat combined with sorafenib enhanced the latter's anti-tumour effects in HCC. The underlying mechanism was regulation of cyclin-CDK/p-RB-mediated G0/G1 cell-cycle arrest, bcl-2/caspase-3-mediated apoptosis, and inhibiting the mTOR pathway to activate autophagy. Our findings strongly suggest that this combination therapy is a potential treatment option against HCC.

\section{Abbreviations}

AKR1B10: aldo-keto reductase 1B10; HCC: hepatocellular carcinoma; IHC: immunohistochemistry (IHC); mTOR: mammalian target of rapamycin; CDK: cyclin-dependent kinase; LC3: microtubule-associated protein light chain3; $\mathrm{p}-\mathrm{Rb}$ : phosphorylated retinoblastoma protein; Bcl-2: B-cell lymphoma-2; ERK: extracellular regulated kinase; AKT: protein kinase B; Bax: BCL2-Associated X; Beclin-1: Bcl-2-interacting protein-1 (Beclin-1); CCK-8: Cell Counting Kit-8 assay.

\section{Acknowledgements}

Thanks for the technical support from Dr. Yanwei Li and Dr. Chao Han. This study was supported by "Thirteenth Five-Year Plan" Major National Science and Technology Major Projects (2017ZX10202203) and Liaoning Provincial Science and Technology Planning Project (2013225021).

\section{Competing Interests}

The authors have declared that no competing interest exists.

\section{References}

1. Bray F, Ferlay J, Soerjomataram I, Siegel RL, Torre LA, Jemal A. Global cancer statistics 2018: GLOBOCAN estimates of incidence and mortality worldwide for 36 cancers in 185 countries. CA Cancer J Clin. 2018; 68: 394-424.

2. Forner A, Reig M, Bruix J. Hepatocellular carcinoma. The Lancet. 2018; 391: 1301-14.

3. Ogunwobi OO, Harricharran T, Huaman J, Galuza A, Odumuwagun O, Tan $\mathrm{Y}$, et al. Mechanisms of hepatocellular carcinoma progression. World J Gastroenterol. 2019; 25: 2279-93

4. Llovet JM, Ricci S, Mazzaferro V, Hilgard P, Gane E, Blanc JF, et al. Sorafenib in advanced hepatocellular carcinoma. N Engl J Med. 2008; 359: 378-90.

5. Zhu AX, Duda DG, Sahani DV, Jain RK. HCC and angiogenesis: possible targets and future directions. Nat Rev Clin Oncol. 2011; 8: 292-301. 
6. Ye X, Li C, Zu X, Lin M, Liu Q, Liu J, et al. A Large-Scale Multicenter Study Validates Aldo-Keto Reductase Family 1 Member B10 as a Prevalent Serum Marker for Detection of Hepatocellular Carcinoma. Hepatology. 2019; 69: 2489-501.

7. Matkowskyj KA, Bai H, Liao J, Zhang W, Li H, Rao S, et al. Aldoketoreductase family $1 \mathrm{~B} 10$ (AKR1B10) as a biomarker to distinguish hepatocellular carcinoma from benign liver lesions. Hum Pathol. 2014; 45: 834-43.

8. Heringlake S, Hofdmann M, Fiebeler A, Manns MP, Schmiegel W, Tannapfel A. Identification and expression analysis of the aldo-ketoreductase1-B10 gene in primary malignant liver tumours. J Hepatol. 2010; 52: 220-7.

9. Ha SY, Song DH, Lee JJ, Lee HW, Cho SY, Park CK. High expression of aldo-keto reductase $1 \mathrm{~B} 10$ is an independent predictor of favorable prognosis in patients with hepatocellular carcinoma. Gut Liver. 2014; 8: 648-54.

10. Han C, Gao L, Bai H, Dou X. Identification of a role for serum aldo-keto reductase family 1 member B10 in early detection of hepatocellular carcinoma. Oncology Letters. 2018; 16(6):7123-7130

11. Han $\mathrm{C}$, Gao L, Zhao L, Sheng $\mathrm{Q}$ Z Zhang $\mathrm{C}$, An Z, et al. Immunohistochemistry Detects Increased Expression of Aldo-Keto Reductase Family 1 Member B10 (AKR1B10) in Early-Stage Hepatocellular Carcinoma. Medical Science Monitor. 2018; 24: 7414-23.

12. Jin $Y Y$, Han $C$, Geng N, Li YR, Zheng LY, Zhu WJ, et al. AKR1B10 inhibitor enhances the inhibitory effect of sorafenib on liver cancer xenograft. Zhonghua gan zang bing za zhi. 2019; 27: 39-44.

13. Giménez-Dejoz J, Weber S, Fernández-Pardo Á, Möller G, Adamski J, Porté S, et al. Engineering aldo-keto reductase $1 \mathrm{~B} 10$ to mimic the distinct $1 \mathrm{~B} 15$ topology and specificity towards inhibitors and substrates, including retinoids and steroids. Chemico-biological interactions. 2019; 307: 186-94.

14. Luo D, Bu Y, Ma J, Rajput S, He Y, Cai G, et al. Heat shock protein 90-a mediates aldo-keto reductase 1B10 (AKR1B10) protein secretion through secretory lysosomes. The Journal of biological chemistry. 2013; 288: 36733-40.

15. Nassour J, Radford R, Correia A, Fusté JM, Schoell B, Jauch A, et al. Autophagic cell death restricts chromosomal instability during replicative crisis. Nature. 2019; 565: 659-63.

16. Galluzzi L, Kepp O, Kroemer G. Mitochondria: master regulators of danger signalling. Nature Reviews Molecular Cell Biology. 2012; 13: 780-8.

17. Wang K. Autophagy and apoptosis in liver injury. Cell cycle. 2015; 14: 1631-42.

18. Amaravadi RK, Kimmelman AC, Debnath J. Targeting Autophagy in Cancer: Recent Advances and Future Directions. Cancer Discov. 2019; 9: 1167-81.

19. Lee YJ, Jang BK. The Role of Autophagy in Hepatocellular Carcinoma. Int J Mol Sci. 2015; 16: 26629-43.

20. Allaire M, Rautou PE, Codogno P, Lotersztain S. Autophagy in liver diseases: Time for translation? J Hepatol. 2019; 70: 985-98.

21. Matter MS, Decaens T, Andersen JB, Thorgeirsson SS. Targeting the mTOR pathway in hepatocellular carcinoma: Current state and future trends. Journal of Hepatology. 2014; 60: 855-65.

22. Tanaka S, Arii S. Molecular targeted therapies in hepatocellular carcinoma. Seminars in oncology. 2012; 39: 486-92.

23. Zhu YJ, Zheng B, Wang HY, Chen L. New knowledge of the mechanisms of sorafenib resistance in liver cancer. Acta Pharmacol Sin. 2017; 38: 614-22

24. Chen J, Jin R, Zhao J, Liu J, Ying H, Yan H, et al. Potential molecular, cellular and microenvironmental mechanism of sorafenib resistance in hepatocellular carcinoma. Cancer Lett. 2015; 367: 1-11.

25. Lin Z, Zhang X, Zhao F, Ru S. Bisphenol S promotes the cell cycle progression and cell proliferation through ERa-cyclin D-CDK4/6-pRb pathway in MCF-7 breast cancer cells. Toxicol Appl Pharmacol. 2019; 366: 75-82.

26. Mukhopadhyay S, Panda PK, Sinha N, Das DN, Bhutia SK. Autophagy and apoptosis: where do they meet? Apoptosis. 2014; 19: 555-66.

27. Yue Z, Guan X, Chao R, Huang C, Li D, Yang P, et al. Diallyl Disulfide Induces Apoptosis and Autophagy in Human Osteosarcoma MG-63 Cells through the PI3K/Akt/mTOR Pathway. Molecules. 2019; 24: 2665-78.

28. Ciccarone F, Castelli S, Ciriolo MR. Oxidative Stress-Driven Autophagy acROSs Onset and Therapeutic Outcome in Hepatocellular Carcinoma. Oxidative Medicine and Cellular Longevity. 2019; 2019: 1-10.

29. Sui X, Chen R, Wang Z, Huang Z, Kong N, Zhang M, et al. Autophagy and chemotherapy resistance: a promising therapeutic target for cancer treatment. Cell Death Dis. 2013; 4: e838.

30. Prieto-Dominguez N, Ordonez R, Fernandez A, Garcia-Palomo A, Muntane J, Gonzalez-Gallego J, et al. Modulation of Autophagy by Sorafenib: Effects on Treatment Response. Front Pharmacol. 2016; 7: 151-66.

31. Zhai B, Hu F, Jiang X, Xu J, Zhao D, Liu B, et al. Inhibition of Akt reverses the acquired resistance to sorafenib by switching protective autophagy to autophagic cell death in hepatocellular carcinoma. Mol Cancer Ther. 2014; 13: 1589-98.

32. Baba SP, Zhang D, Singh M, Dassanayaka S, Xie Z, Jagatheesan G, et al. Deficiency of aldose reductase exacerbates early pressure overload-induced cardiac dysfunction and autophagy in mice. J Mol Cell Cardiol. 2018; 118: 183-92.

33. Yu X-N, Chen H, Liu T-T, Wu J, Zhu J-M, Shen X-Z. Targeting the mTOR regulatory network in hepatocellular carcinoma: Are we making headway? Biochimica et Biophysica Acta (BBA) - Reviews on Cancer. 2019; 1871: 379-91.

34. Huang C, Cao Z, Ma J, Shen Y, Bu Y, Khoshaba R, et al. AKR1B10 activates diacylglycerol (DAG) second messenger in breast cancer cells. Mol Carcinog. 2018; 57: 1300-10.

35. Ramana KV, Tammali R, Srivastava SK. Inhibition of aldose reductase prevents growth factor-induced G1-S phase transition through the
AKT/phosphoinositide 3-kinase/E2F-1 pathway in human colon cancer cells. Mol Cancer Ther. 2010; 9: 813-24.

36. Tammali R, Saxena A, Srivastava SK, Ramana KV. Aldose reductase inhibition prevents hypoxia-induced increase in hypoxia-inducible factor-1alpha (HIF-1alpha) and vascular endothelial growth factor (VEGF) by regulating 26 $\mathrm{S}$ proteasome-mediated protein degradation in human colon cancer cells. J Biol Chem. 2011; 286: 24089-100. 